\title{
WHAT FACTORS PREDICT THE SELF-IDENTIFICATION OF DRUG DEPENDENCY AMONG CRIMINAL JUSTICE POPULATIONS? PREVALENCE, CORRELATES, AND IMPLICATIONS FOR THE CRIMINAL JUSTICE SYSTEM
}

\author{
A PREPRINT \\ Cameron T. Langfield* \\ Centre for Social Research and Methods \\ Australian National University \\ Jason L. Payne \\ Centre for Social Research and Methods \\ Australian National University \\ This is the pre-print version of this article. The published article can be found at the following link: \\ Langfield, C. T., \& Payne, J. L. (2021). What Factors Predict the Self-Identification of Drug Dependency Among Australian \\ Police Detainees? Prevalence, Correlates, and Implications for the Criminal Justice System. Journal of Drug Issues, 51(1), \\ 3-22. https://doi.org/10.1177/0022042620952768
}

${ }^{*}$ Corresponding author:cameron. langfield@anu.edu.au 


\begin{abstract}
The drug-crime nexus has long received international interest from both drug-crime scholars and public policy experts worldwide. While there is little disagreement that more frequent drug use is linked to higher rates of crime the causal underpinnings of this relationship remain hotly contested. One area of increasing interest among criminological, social, and psychological scholars alike is the confounding influence and power of 'identity' in shaping the long-term behavioural trajectories of both drug use and crime. In this study, we explore the prevalence with which recent drug using police detainees self-identify as drug dependent and, using logistic regression, we model self-identification as a function of one's demographic, and drug use profile. We find that, after controlling for type, frequency, and longevity of drug use, being female and younger is associated with an increased odds of self-identifying as drug dependent. Further, we find that despite using drugs at the same frequency and for the same length of time, heroin and other opiate users are the most likely to self-identify. To end, the potential implications of these results are discussed, and future research avenues are explored.
\end{abstract}

\title{
1 Introduction
}

A foundation of the contemporary criminal justice response to drug use and crime has been to offer judicially-supervised or court-mandated treatment to those offenders with a dependency on drugs (Cooper, 2003; Freeman, 2001; Freiberg, Payne, Gelb, Morgan, \& Makkai, 2016; Kornhauser, 2018; Logan \& Link, 2019; Mackinem \& Higgins, 2008; Payne, 2008; Shaffer, 2011). Broadly classified as therapeutic jurisprudence (Hora, Schma, \& Rosenthal, 1998; Spencer, 2012), this prioritisation of treatment is supported by decades of research which has shown that incarceration rarely rehabilitates the drug using offender (see, for example, Chandler, Fletcher, \& Volkow, 2009; Pearson \& Lipton, 1999) nor does it significantly ameliorate the welldocumented correlation between drug use and crime (Anglin \& Speckart, 1986; Bennett \& Holloway, 2003, 2009; Bennett, Holloway, \& Farrington, 2008; Brochu, Brunelle, Plourde, \& Da Silva, 2018; Chaiken \& Chaiken, 1990; Makkai \& Payne, 2003b; Wagner \& Anthony, 2002; Weatherburn, Topp, Midford, \& Allsopp, 2000). Key to the success of these therapeutic approaches has been the growing recognition of drug dependency as a complex phenomenon (Bergquist, Fox, \& Sinha, 2010; Burr, 1987; Dahl, 2015; Eddy, Halbach, Isbell, \& Seevers, 1965; Johnson, 2006; Ladwig \& Andersen, 1989; McIntosh \& McKeganey, 2001; Reed, 1985; Volkow \& Li, 2004; Volkow et al., 2011; Wasilow-Mueller \& Erickson, 2001); one that acknowledges the compulsive condition as a social construct that is neither linearly related to the frequency of drug use nor universal in its manifestation across the offending population (Babor et al., 2007; Gossop et al., 1995; Volkow \& Li, 2004; Volkow et al., 2011; Volkow et al., 1999).

While our understanding of dependency has significantly evolved in recent decades, and while our systems of screening and clinical assessment have matured, still there is a heavy reliance on self-reported dependency as an initial triaging protocol (Freiberg et al., 2016; Logan \& Link, 2019; Payne, 2005, 2006; Payne \& Morgan, 2016). Indeed, of the various drug diversion and drug court programs that operate worldwide, consent and volunteerism are core requirements, so in many respects, selfidentification remains an important gateway to treatment (see Freiberg et al., 2016). As a result, some offenders may be inadvertently denied treatment because they do not self-identify, and some cohorts of offenders may be at greater disadvantage if self-identification is affected by social and structural factors that condition their drug use experience. These inequalities demand academic scrutiny.

\subsection{Dependency as a gateway to treatment}

For the more than 50 years, criminologists have documented a strong positive correlation between drug use and crime. The results of this work have been mixed, but the meta-story of this research is that a majority of offenders in police custody (Bennett \& Holloway, 2005; Bennett, Holloway, \& Farrington, 2008; Chaiken \& Chaiken, 1990; Freeman \& Fitzgerald, 2002; Patterson, Sullivan, Ticehurst, \& Bricknell, 2018; Voce \& Sullivan, 2019) and prison (Bennett \& Holloway, 2009; Makkai \& Payne, 2003a, 2003b) have a history of drug use and community samples of drug users have higher rates of criminal justice contact than their non-drug using peers (Anglin \& Perrochet, 1998; Anglin \& Speckart, 1986, 1988; Stafford \& Bums, 2013). Further, within the offending population rates of criminal offending are highest among those who are regular or compulsive drug users (Anglin \& Perrochet, 1998; Anglin \& Speckart, 1986; Bennett \& Holloway, 2005, 2009; Bennett et al., 2008; Prichard \& Payne, 2005), and periods of reduced drug use of abstinence, whether triggered by treatment or not, are consistently linked to a decline in criminal participation (French \& Zarkin, 1992; Payne, 2005; Payne, 2008; Payne \& Morgan, 2016; Rajkumar \& French, 1997). Finally, post-release recidivism is highest among those who enter prison with a dependency on drugs and higher still among those who report an intention to return to drug use upon their release (Kinner, 2006).

The relative failure of imprisonment as a period of forced abstinence and the high rates of recidivism among drug dependent offenders was inspiration for the establishment of the world's first drug court in Miami-Dade County, Florida, in the late 1980s. Since then, drug courts have proliferated internationally (Cooper, 2003; Kornhauser, 2018; Logan \& Link, 2019; Mitchell, 
Wilson, Eggers, \& MacKenzie, 2012; Payne, 2006; Payne, 2008; Payne \& Morgan, 2016; Shaffer, 2011; Shannon, Jones, Newell, \& Payne, 2018; Tiger, 2013) and the guiding principle of therapeutic jurisprudence (Hora, Schma, \& Rosenthal, 1998; Spencer, 2012) has made a solid mark on criminal justice systems worldwide. In Australia, the diversion and treatment of drug users is organised on a continuum (see Wundersitz, 2007 for an overview) from the early intervention and diversion of low-level users to the intensive court-supervised drug court programs which are offered as a last resort alternative to imprisonment.

For the majority of programs worldwide, participant consent is a core requirement (Payne \& Morgan, 2016) and such consent often requires the offender to volunteer information about their status as a drug user. Whether an offender is admitted to a drug court is often subject to a comprehensive battery of assessment that includes diagnostic screening and clinical interviews, but still an offender must advise legal counsel of their intention to be treated and their consent to be diverted. Identifying oneself as 'drug dependent' and 'in need of treatment' is, therefore, a necessary precondition for many diversion programs. For this reason, it is essential that we better understand how many drug-using offenders self-identify as drug dependent and whether self-identification is more or less common among different demographic groups in the criminal justice system.

\subsection{Demographics and identity}

Our instinct is that the propensity to self-identify as drug dependent is not shared equally across the criminal justice population because dependency is as much (though, probably more so) a manifestation of social and cultural values as it is connected to the level or severity of use. Even the Diagnostic and Statistical Manual of Mental Disorders (DSM-V) classifies substance use disorders as more than just a measure of how much of a drug a person is using, but rather the continued use of drugs despite considerable personal and social consequences (Proctor \& Hoffmann, 2016; Sproule, Busto, Somer, Romach, \& Sellers, 1999). For this reason, we believe that some offenders (women, young people, and Indigenous offenders, in particular) are more likely to self-identify as drug dependent even after holding constant their longer term and very recent drug use experience.

Women, for example, are more likely than men to experience the negative affective consequences of their drug use and this gender differential is likely to promote the internalisation of a dependent identity (Broom \& Stevens, 1991; Cormier, Dell, \& Poole, 2004; Donath, 2003; Poole \& Dell, 2005; Shand, Degenhardt, Slade, \& Nelson, 2010; Tuchman, 2010; Wasilow-Mueller \& Erickson, 2001). In their study, Tuchman (2010) found that women may develop different drug using behaviours depending on their social situation and this may, in turn, affect the manifestation of their dependency. Further, gender differences may also be explained by the differential social and physiological effects of drug use that are experienced differently for men and women (Johnson, 2006). For example, research has shown that female drug users are more likely to be victims of sexual, physical, and emotional violence (Ladwig \& Andersen, 1989; Tuchman, 2010; Wasilow-Mueller \& Erickson, 2001) and that women are more likely to use drugs and alcohol as a method of coping with the strictures of their social roles (Cormier et al., 2004; Shand et al., 2010 \& Nelson, 2010). Consequently, women's drug use is more likely to be framed as problematic and dangerous compared to male standards (Bull, 2003; Donath, 2003; Johnson, 2006; Poole \& Dell, 2005; Tuchman, 2010; Wasilow-Mueller \& Erickson, 2001).

Like women, young people and other minority populations are also more likely to be affected by a wider narrative that treats drug use (let alone compulsive drug use) as a direct and particular threat to community values (Chen, Tyler, Whitbeck, \& Hoyt, 2004; Greene, Ennett, \& Ringwalt, 1997; Grinman et al., 2010; McMorris, Tyler, Whitbeck, \& Hoyt, 2002; Stevens et al., 2007). For young and minority populations, therefore, drug use is both the subject of specific disapproval as well as a potentially valuable coping strategy against the pressure of these wider expectations (Thompson, Rew, Barczyk, McCoy, \& Mi-Sedhi, 2009). On this issue, Thompson and colleagues (2009) found that young people often identify drug use as a positive aspect of their (daily) life-and as a method of coping with potentially negative experiences-especially when they are facing other adverse outcomes associated with their involvement with crime and association with delinquent peers (see also Baron, 1999). Similarly, research in Australia has shown that Indigenous Australians are not only significantly overrepresented in the criminal justice system (Australian Institute of Health and Welfare, 2011; Cunneen, 2006; Payne, 2006; Snowball \& Weatherburn, 2006; Weatherburn, 2014; Weatherburn \& Holmes, 2010), but their disproportionate representation as drug users (Putt, Payne, \& Milner, 2005; Weatherburn, 2014) is likely a consequence of a range of factors, including discrimination, cultural dispossession, and economic marginalisation (Australian Institute of Health and Welfare, 2011; Saggers \& Gray, 1998).

\subsection{Identity and treatment}

While understanding the prevalence and dynamics of self-reported dependency is important for improving equity in the criminal justice system, whether an offender self-identifies as drug dependent is also important for another reason. Identity has been shown to be a powerful mediator of antisocial behaviour, including the persistence of both criminal (Asencio, 2013; Asencio \& Burke, 2011; Brezina \& Topalli, 2012; Little, 1990; Rocque et al., 2016; Veysey \& Rivera, 2017) and drug use behaviours separately (Dahl, 2015; Dingle et al., 2015; Mackinem \& Higgins, 2008; McIntosh \& McKeganey, 2001; Neale et al., 2011; Shinebourne \& Smith, 2009; Vryan, Adler, \& Adler, 2003), as well as the correlation between the two (DeLisi, Angton, Behnken, \& Kusow, 2015; Dingle et al., 2015; Erikson, 1968; Everitt \& Robbins, 2016; Howard, 2000; Mackinem \& Higgins, 
2008; McIntosh \& McKeganey, 2001). Criminologists, for example, have long focussed on the principles of interactionism and the evolution of antisocial identities as an explanation for both criminal persistence (H Becker, 1953; HS Becker, 1963; Erikson, 1968; Lemert, 1951; Mead, 1934) and desistance (Hammersley, 2011; Maruna, Lebel, Mitchell, \& Naples, 2004; Paternoster, Bachman, Bushway, Kerrison, \& O'Connell, 2015; Paternoster, Bachman, Kerrison, O'connell, \& Smith, 2016; Paternoster \& Bushway, 2009; Rocque, Posick, \& Paternoster, 2016; Veysey \& Rivera, 2017). Public health scholars, on the other hand, have focused on the influence of 'drug dependency' identities and their capacity to precipitate compulsive drug use behaviours even in the face of significant personal and social consequences (see, for example, Kelly, Bergman, \& Vilsaint, 2016; May, 2001; Spooner \& Hetherington, 2005).

The concept of 'identity' has yet to be consolidated under single or universal definition; however, broadly, it refers to an understanding and/or self-identification of 'who I am' (Bamberg, 2011; Paternoster \& Bushway, 2009; Rocque et al., 2016). Individuals can be represented by multiple identities and these identities can be used across a variety of situations (Bamberg, 2011; Mead, 1934; Oyserman, 2004; Oyserman, Elmore, \& Smith, 2012). It has been postulated that these identities amalgamate into one's overall 'self-concept', which can be loosely defined as a set of ideas that individuals believe about themselves (Brownfield \& Thompson, 2005; Oyserman, 2004; Oyserman et al., 2012) and is the individual's interpretation of their identities, their connections with others, their encounters with other social groups, and their emotional states (Oyserman et al., 2012).

Importantly, identity theory has more recently emphasised the value of the agentic and non-agentic action that occurs as a consequence of identity reformation. In their study of regular drug users, Waldorf and Biernacki (1981) found that desistance from regular drug use arose when the individual's 'addict' identity came into conflict with their other, 'socially acceptable' identities (i.e. 'father' or 'mother'). They argued that the process of desisting from regular drug use was a process by which an individual learns to manage a so-called "spoiled identity" (Neale et al., 2011) - something which is achieved by the restoration of a previous, socially acceptable identity, or the establishment of a new, 'non-addict' identity.

Similarly, Dingle and colleagues (2015) found that for some individuals drug dependency often signalled the loss of socially desirable identities. In their study, desistance from drug use was shown to have been triggered by the desire to restore past, socially acceptable identities when the drug dependency identity was associated with negative affective experiences. Conversely, Dingle and colleagues (2015) also documented that for some drug users their identity as dependent fostered relationships which solidified their sense of self and strengthened their connection to other drug using peers. What matters here is that for some individuals regular illicit drug use becomes such a positive and significant element of their identity that it may feature heavily in their private and public stories and these drug users are much less likely to desist or seek treatment.This has implications for how we as scholars come to understand persistent drug use as a manifest outcome of identity formation.

If identity serves as an important multiplier of both drug use and crime, it also likely influences the efficacy of drug treatment programs when targeted to offenders in the criminal justice system (Dingle et al., 2015; Kornhauser, 2018; Logan \& Link, 2019; Mackinem \& Higgins, 2008; McIntosh \& McKeganey, 2001; Tiger, 2013; Veysey \& Rivera, 2017).Through the many international evaluations of drug courts (see, for example, Freiberg et al., 2016; Kornhauser, 2018; Logan \& Link, 2019; Mitchell, Wilson, Eggers, \& MacKenzie, 2012; Payne, 2005, 2008; Shaffer, 2011), we now know that program success is maximised when treatment and intervention modalities are suitably targeted to the severity of need. However, this 'need' is often operationalised as the quantity and frequency of drug use, not the strength of drug-using identities. Failure to account for identity as an important 'third variable' may weaken program outcomes which do not tackle identity reformation as a core component of treatment. Similarly, if different demographic cohorts are more or less inclined to self-identify, then these 'identity' focused treatment modalities may also need to be differentially targeted. Our efforts to estimate the prevalence and correlates of self-identified drug dependence among recent drug users in the criminal justice system is, therefore, an important objective for public policy.

\subsection{Aims and objectives}

This study offers a large-sample quantitative analysis of recent drug users appearing before the Australian criminal justice system and seeks to estimate the prevalence of self-identified drug dependency and its drug use correlates. In addition, this study aims to identify demographic inequalities which persist even after the frequency, longevity, and type of drug use are held constant. To achieve this, we ask two questions of the data: (1) how many recent drug users within the criminal justice system identify as drug dependent; and (2) is the propensity to self-identify conditioned on key demographic and drug use variables. 


\section{Methodology}

\subsection{Data and measures}

\subsection{Data}

We draw our data from the Australian Institute of Criminology's (AIC) Drug Use Monitoring in Australia (DUMA) program (Patterson, Sullivan, Ticehurst, \& Bricknell, 2018; Voce \& Sullivan, 2019). DUMA is Australia's largest and longest running survey of police detainees (Gannoni \& Goldsmid, 2017) and is the methodological cousin of the US Arrestee Drug Abuse Monitoring Program (ADAM) (U.S. Department of Justice, 2002). In Australia, DUMA operates quarterly, and data is gathered over a four-week period. During this time, a census of all detainees is attempted except where access to a detainee is restricted by the Watch-house Sergeant, usually on safety grounds. From each detainee, the data collection procedure gathers official administrative data for the current period of detention, as well as interviewer-administered self-report data on demographics, prior offending and current drug use. At the completion of the survey, each detainee is asked to provide a urine specimen for drug testing. Urinalysis is voluntary (Makkai, 1999) and has been a vital tool for self-report validation and verification. The DUMA program has received ethical review clearance by the AIC's Human Research Ethics Committee and the authors' access to this data has been facilitated by the Australian Data Archive with the permission of the AIC.

\subsection{Measures}

The main variable of interest in this study is a detainees' self-identification as drug dependent. In DUMA, each detainee is asked a series of questions regarding their history of use for nine different drug types. These are heroin, cannabis, cocaine, amphetamine, ecstasy, LSD, inhalants, benzodiazepines, and morphine. For the latter two prescription drugs, detainees are only asked to report on any illegal use. Where a detainee affirms the use of a drug in the past 12 months, they are then asked whether they felt they 'needed or were dependent' on that drug. A detainee is asked this separately for each drug type and for the purposes of this study they are coded as self-identifying if they said 'yes' for any drug type.

In estimating the prevalence of self-identification, we condition the analysis on three variables that operationalise a drug using career-namely, the type of drug being used, the frequency of that use, and the longevity of drug use overall. First, we identified each detainee's drug of primary use (primary drug), which denotes the drug type for which they have the highest frequency of use in the 30 days prior to their most recent arrest. In a small number of cases, a detainee might report the use of two drugs at an equal frequency and so self-reported dependency was used to classify the primary drug. Detainees who could not be otherwise classified (because they self-reported dependency on two drugs with an equal frequency of use) were then categorised according to the most serious of the drugs they were using. Second, we created a variable which measures the self-reported frequency of primary drug use in the past 30 days. This variable measures the number of days of use (between 0 and 30), not the actual quantity or number of episodes of use. Third, we created a variable which measures the length of overall drug use for each detainee. The number of years was calculated as the interval between the self-reported age of first drug use and the detainee's current age. This was then categorised into four groups measuring initiation in the last two years, initiation between three and five years ago, initiation between six and 10 years ago, and initiation longer than 10 years ago.

The demographic covariates included in this study were gender (coded 0 for females and 1 for males), age at arrest which was coded into 5 groups (18-25 years, 26-35 years, 36-45 years, 46-55 years and 56+ years), and Indigenous status (coded 0 for non-Indigenous and 1 for Indigenous). For an overview of the sampling selection process, see Table 1. For sample descriptive statistics, see Table 2.

Table 1: Sampling selection outcomes

\begin{tabular}{lcc}
\hline & $\mathrm{N}$ & $\%$ \\
\hline Detainees approached (initial sample) & 31,750 & 100.0 \\
Detainees interviewed & 22,474 & 70.1 \\
Detainees who reported any drug use in the past 30 days (final sample) & 14,475 & 64.4 \\
Detainees self-identified as dependent (\% of final sample) & 7,618 & 52.6 \\
\hline Source: Australian Institute of Criminology - Drug Use Monitoring Australia 2004-2010 [computer file]
\end{tabular}

\subsection{Analytical approach}

The primary objective of this study is to estimate the proportion of detainees who self-identify as dependent on illicit drugs and explore whether self-identification varies by gender, age, and Indigenous status, holding constant the frequency, type, and longevity of use. Since our dependent variable is dichotomous (0/1) we use the logistic regression method to model the probability of self-identification as a multivariate function of both demographic and drug use indicators. 


\section{Results}

Of the 14,475 detainees who had used drugs in the past 30 days, the majority were non-Indigenous $(83 \%$, N=11,955), male $(84 \%, \mathrm{~N}=12,115)$ and the average age was $30.8(\mathrm{SD}=9.9)$. In terms of drug use, the majority in this sample were primary users of cannabis $(63 \%, \mathrm{~N}=9,141)$, followed by speed and ecstasy $(21 \%, \mathrm{~N}=3,092)$ and heroin and other opiates $(11 \%, \mathrm{~N}=1,688)$. Most had been using drugs for 10 or more years and a majority had been using drugs for 16 or more days per month in the past 30 days. Overall, 53 percent of this sample self-identified as dependent on at least one drug (Table 2). At the bivariate level, self-identification was highest for heroin and other opiate users $(86 \%)$ and lowest for primary users of cocaine $(32 \%)$. Overall, the differences between users of different drugs was statistically significant $\left(\mathrm{X}^{2}=920.67, p<.001\right)$. Proportionally, the representation of heroin, cocaine, and other drug users is small but the sample sizes for each of these categories is not too small for discrete categorisation.

In terms of frequency of primary drug use, self-identification was most common among the highest frequency users $\left(\mathrm{X}^{2}=2.9 \mathrm{e}+02, p<.001\right)$. For instance, three in every four very regular users (16 or more days) identified as dependent. This compares to a self-identification rate of 50 percent among those who reported use of between 9 and 15 days and 24 percent among those who reported use of between 1-8 days. ${ }^{2}$ Finally, self-identification was highest for users who had been using drugs over a longer period of time $\left(\mathrm{X}^{2}=309.74, p<.001\right)$.

Bivariate analyses by age, gender, and Indigenous status show that self-identification was higher for women than for men $\left(\mathrm{X}^{2}=64.39, p<.001\right)$ and higher for younger detainees than older detainees $\left(\mathrm{X}^{2}=89.18, p<.001\right)$. Indigenous status was not significant at the bivariate level $\left(\mathrm{X}^{2}=1.64, p>.05\right)$. These bivariate results reflect the average relationships within the data, but do not account for the inequalities that might exist between groups across other covariates. For example, the difference between male and female detainees may result not because of an inherent difference that is related to one's gender, but because men are more likely to use heroin, or use drugs at a higher frequency than women.

To test the independent effects of each covariate we employ a logistic regression model. In the Model 1, we explore the independent effects of drug type, drug use frequency, and the longevity of overall drug use as these are the baseline covariates which need to be held constant when testing the demographic effects in Model 2. Consistent with the bivariate analyses, both drug type, longevity of use and frequency of use are statistically related to the probability that a detainee will self-identify as drug dependent. The longer a detainee has been using the higher the probability of self-identification. Furthermore, net of the differences between drug types, the more frequent a detainee uses drugs, the higher the probability $(b=0.09, p<.001)$ that they will identify as dependent. Conversely, the model also indicates that holding constant the frequency of use there remains strong drug-specific effects, with heroin users the most likely to self-identify as drug dependent.

In Model 2, which was a better fit for the data (LL=-7875.56 for Model 1 vs. LL=-7821.22 for Model 2), the difference between male and female detainees holds even after controlling for drug type, drug use frequency, years of use, and age. A female detainee is statistically more likely to self-identify as dependent even if she is the same age, uses the same drug, and uses drugs at the same frequency as her male counterpart. Age is also statistically significant, net of the effects of other covariates, with younger detainees more likely to self-identify than their older peers. Consistent with the bivariate analysis described above, identifying as Indigenous was not statistically significant nor related to a higher probability identifying oneself as dependent.

\section{Discussion}

This study began with a simple objective-to estimate the prevalence of self-reported drug dependency and describe those drug use and demographic factors which are associated with a higher probability of self-identification. To achieve this, we capitalised on secondary data analysis of the Australian DUMA program using bivariate and multivariate methods. Our efforts were motivated by a growing qualitative literature that situates drug using identities as an important, albeit oft-forgotten, 'thirdvariable' or 'multiplier' in the empirical analysis of the drug-crime relationship. To this end, we offer one of the first large-scale quantitative studies of self-identified drug dependency among a national sample of police detainees. We explore whether there exists any differential propensity to self-identify by gender, age and Indigenous status. These results offer a unique perspective on the nature of drug dependency as a social and cultural phenomenon-one which has the potential to affect the efficacy of those criminal justice system interventions designed to target and treat drug using offenders.

Our results indicate that 53 percent of recent drug users identify as dependent on drugs. This is highest for the most regular of users, those who have used for longer periods of time, and highest for heroin and other opiate users when the frequency of drug use is held constant. Of the demographic variables, these data indicate that women are more likely than men to self-identify as dependent and younger detainees are more likely than older detainees. Clearly, identifying oneself as drug dependent is not

\footnotetext{
${ }^{2}$ Supplementary analysis showed that the frequency of use was higher, on average, for heroin and morphine users than for cannabis, amphetamine or cocaine users. It is this between-drug variability which necessitates a multivariate model that controls for both frequency, longevity and drug type.
} 
Table 2: Descriptive statistics of final sample $(n=14,475)$

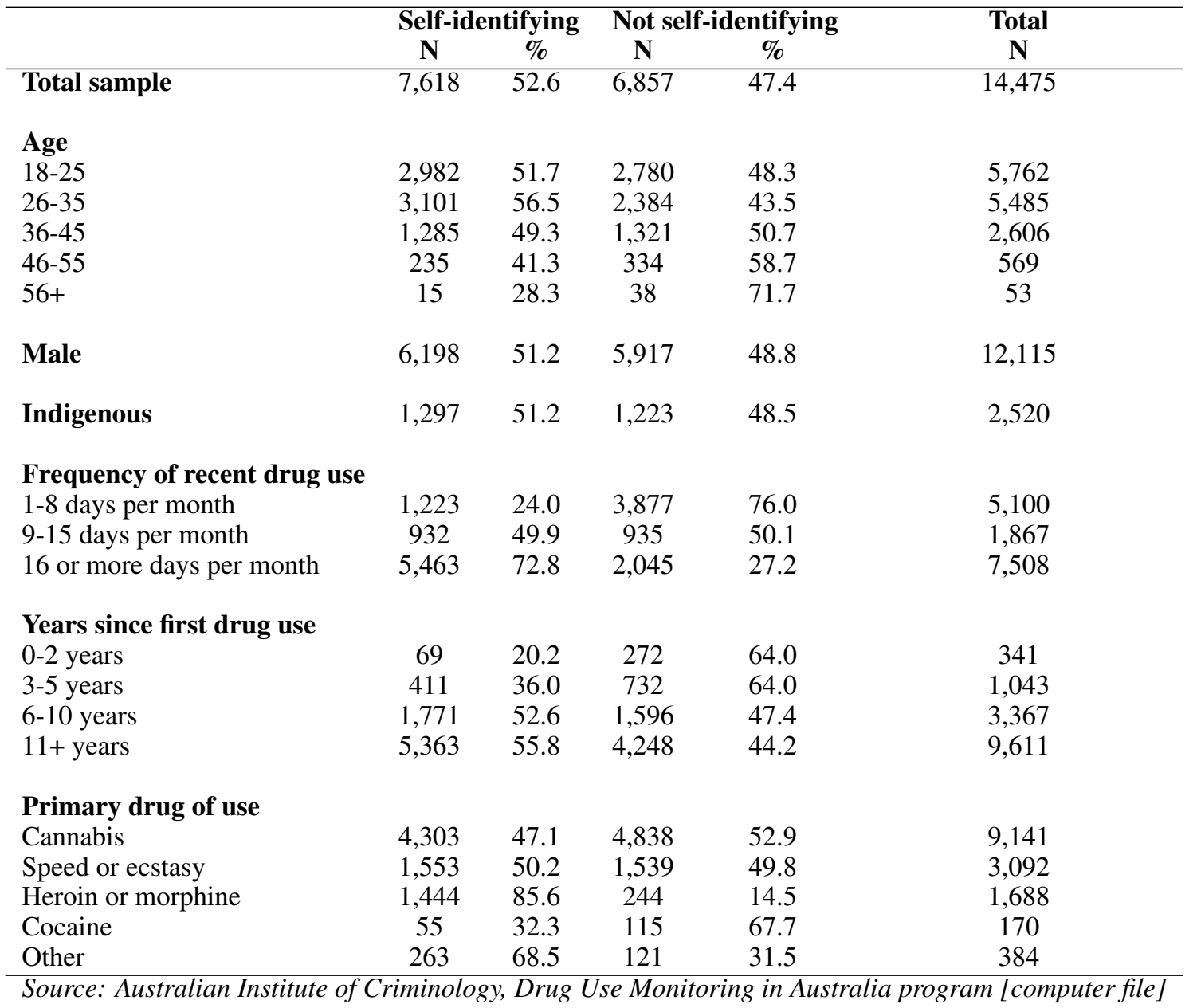

simply a function of how much of a drug one uses, but the cultural and social symbolism of drug use as it is conditioned by social interactions and meanings that are unequal across the criminal justice population.

\subsection{Demographics}

In this study, women were found to be statistically more likely to self-report a dependency. This is perhaps not surprising, given research in this space has consistently found that women's experience of drug dependency is different (see Broom \& Stevens, 1991; Cormier, Dell, \& Poole, 2004; Donath, 2003; Poole \& Dell, 2005; Shand, Degenhardt, Slade, \& Nelson, 2010; Tuchman, 2010; Wasilow-Mueller \& Erickson, 2001). For example, it has been shown that the developmental trajectory for women, from initial use to drug dependency, is often quicker and more often correlated with adverse life experiences (Kosten et al., 1996; Piazza, Vrbka, \& Yeager, 1989; Randall et al., 1999; Tuchman, 2010; Westermeyer \& Boedicker, 2000) and although women comprise a smaller proportion of all offenders, it is believed that when they are involved with crime, their substance use is more closely associated with their criminality when compared to men (Pollock, 1999). As Wasilow-Mueller and Erickson (2001) argued, drug dependency is still a highly stigmatised, and often socially isolating phenomena and women are particularly sensitive to both the individual and social effects experienced when admitting they are drug dependent. What this means for the current study, then, is that recent drug using female detainees are perhaps more likely to self-report because they have faced highest costs and consequences of their drug use (Cormier et al., 2004; Shand et al., 2010).

In addition, the current analysis found that younger detainees were more likely to self-identify as dependent—a finding that remained even after the longevity of drug use, drug type, and the frequency of that drug use were held constant. This finding confirms, in our view, that drug use among younger populations is largely influenced by a wider social narrative that frames youth drug use as a significant problem that has direct threats to community efficacy and runs counter to community expectations of youth behaviour (Chen et al., 2004; Greene, Ennett, \& Ringwalt, 1997; Grinman et al., 2010; McMorris et al., 2002; Stevens 
A PREPRINT

Table 3: Logistic regression predicting self-reported dependency by demographics and drug use variables

\begin{tabular}{|c|c|c|}
\hline & $\begin{array}{l}\text { Model 1: Drug Use } \\
\text { (logit coefficient) }\end{array}$ & $\begin{aligned} \text { Model 2: } & \begin{array}{l}\text { Drug Use + Demographics } \\
\text { (logit coefficient) }\end{array}\end{aligned}$ \\
\hline \multicolumn{3}{|l|}{ Years since first drug use } \\
\hline $3-5$ years (vs $0-2$ ) & $0.40 *$ & $0.37 *$ \\
\hline $6-10$ years (vs $0-2$ ) & 0.80 & $0.77 * * *$ \\
\hline $11+$ years (vs $0-2$ ) & 0.86 & $1.08^{* * *}$ \\
\hline Frequency of recent drug use & $0.09 * * *$ & $0.09 * * *$ \\
\hline \multicolumn{3}{|l|}{ Primary drug of use } \\
\hline Other (vs cannabis) & $1.37 * * *$ & $1.33 * * *$ \\
\hline Speed or ecstasy (vs cannabis) & $0.61 * * *$ & $0.60 * * *$ \\
\hline Heroin or morphine (vs cannabis) & $1.98 * * *$ & $1.98 * * *$ \\
\hline Cocaine (vs cannabis) & 0.16 & 0.17 \\
\hline \multicolumn{3}{|l|}{ Gender } \\
\hline Male (vs female) & - & $-0.28 * * *$ \\
\hline \multicolumn{3}{|l|}{ Age Group } \\
\hline $26-35$ (vs $18-25$ ) & - & $-0.19 * * *$ \\
\hline $36-45$ (vs $18-25)$ & - & $-0.44 * * *$ \\
\hline $46-55$ (vs $18-25$ ) & - & $-0.81 * * *$ \\
\hline $56+($ vs $18-25)$ & - & $-1.14 * * *$ \\
\hline \multicolumn{3}{|l|}{ Indigenous status } \\
\hline Indigenous (vs Non-Indigenous) & - & -0.04 \\
\hline Constant & -2.60 & -2.28 \\
\hline $\mathrm{N}$ & 14,462 & 14,460 \\
\hline Log Likelihood & -7875.56 & -7821.21 \\
\hline Chi Square & $\mathrm{X}^{2}(8)=4256.88, p=0.00$ & $X^{2}(14)=4362.79, p=0.00$ \\
\hline
\end{tabular}

et al., 2007). Furthermore, it perhaps represents an opportunity for further early intervention among young people who selfidentify. These individuals may be at the beginning of both an escalation in drug use and also the internalisation of a drug dependent identity (see Baron, 1999; Thompson et al., 2009), and so by targeting treatment programs that aim to reduce both an individual's identification with their dependency as well as the frequency of their drug use, we may reduce their overall involvement with the criminal justice system. Conversely, the failure to incorporate an understanding of identity into treatment may weaken program outcomes, particularly for younger offenders.

\subsection{Primary Drug Types}

The multivariate model illustrated that even after controlling for the three components that operationalise a drug using career, there still existed drug-specific effects. In particular, primary heroin and other opiate users were almost 98 percent more likely to self-identify when compared to cannabis users, for example. This finding is, in our view, not so much a consequence of the type of drug a detainee uses, but rather a reflection of the social construction and social narrative surrounding the use of different drug types. For instance, research has found that different drug types carry with them different social meanings (Allen \& Alberici, 2018; Hughes, Lancaster, \& Spicer, 2011; Shapiro, 2002; Taylor, 2008) and these social meanings are often expressed and experienced by users of these substances in different ways. In Australia, heroin has long been considered a highly problematic and addictive drug (Teesson et al., 2017) and the image of a 'dependent heroin user' has largely been fuelled by pejorative imagery and negative stereotypes, both in media (Hughes et al., 2011; Taylor, 2008) and in film (Allen \& Alberici, 2018). The social narrative surrounding regular heroin use as the last drug in a continuum of drug severity (Teesson et al., 2017) has also fuelled the idea that to use heroin is to be dependent. What this means for regular heroin users, then, is that this 
social narrative and the consequences that flow from it, are likely internalised by these individuals as socially constructed and structured experiences of dependency.

This is also seen in the finding that primary cocaine users were associated with a decreased probability of self-identifying as dependent. Given that the social narrative has long 'pitched' cocaine as an 'up-market drug' (Shapiro, 2002; Taylor, 2008) and one that is mainly used by wealthy individuals (Shapiro, 2002; Taylor, 2008), this is not surprising. The social narrative surrounding cocaine use is likely to be very different compared to heroin users (Hughes et al., 2011), and regular cocaine use is not as likely to be met with the same social disapproval or social stigma as regular heroin use. Therefore, regular cocaine users may be less likely to experience and subsequently internalise the socially isolating effects that these negative appraisals and experiences pose to their sense of identity and self-concept (Brownfield \& Thompson, 2005; Leary \& Tangney, 2011; Lloyd, 2013).

This is further echoed in Payne and Langfield (2020, February 19) who argue that regular cocaine use may not be associated with the same social consequences as regular heroin use due to the structure of these drug markets and the individuals with whom regular users are associating. Payne and Langfield (2020, February 19) argue that regular cocaine users are unlikely to be associating with street-level drug market participants but are potentially able to legitimately afford their drug of choice-i.e. through a regular dealer or from a 'legitimate' source (Caulkins et al., 2016; Hser, Huang, Brecht, Li, \& Evans, 2008). Heroin users are more likely to be engaged in a street-based drug market more frequently, therefore increasing the opportunities for contact with the police (Caulkins et al., 2016) and increasing the opportunities to form strong drug-using, offending, and criminal peer-based identities (Bamberg, 2011; Burke \& Reitzes, 1981; Dahl, 2015; Dingle et al., 2015; Howard, 2000). These identities become internalised and begin to form the way the individual views the world and subsequently how they experience their dependency (Dahl, 2015; Dingle et al., 2015; Oyserman et al., 2012). The finding, then, that heroin and cocaine using detainees are associated with varying probabilities of self-reporting as dependent largely confirms, in our view, that the social narrative surrounding (regular) heroin and (regular) cocaine use may be qualitatively and quantitatively different (Scheibe, 2017; Taylor, 2008).

\subsection{Limitations and conclusions}

In drawing this study to a close, we are to be reminded that 'measurement is befuddled with error' (McNemar, 1946, p. 146) and that this study is no exception. In particular, as a secondary analysis, the current research is constrained by data available to us. Furthermore, drug using identities and the nature of drug dependency are a multifaceted phenomenon and are therefore difficult to measure quantitatively. Many of the variables used in this study were single, dichotomous, and self-report items, and critics of the current method may be correct in arguing that the DUMA survey should have included multiple items measuring identity. This, perhaps, would have created a more complex and comprehensive measure of someone's drug dependency and the extent to which they identify with this. However, greater complexity does not always guarantee a more reliable dataset or analysis, and our reliance on a single item measuring self-reported dependency provides an early foray into a previously unexplored area of research. Future research should aim to improve the measures utilised in this study to provide further insight into this complex phenomenon.

Furthermore, we recognise the potential for deception and/or embellishment among this data and the implications this has for treatment programs that rely on self-report measures. For many drug dependent offenders, drug treatment programs-such as Drug Courts here in Australia (Cooper, 2003; Freiberg et al., 2016; Kornhauser, 2018; Logan \& Link, 2019; Payne, 2008; Payne \& Morgan, 2016) — are often an alternative to imprisonment. For scholars within this space (see, for example, Cooper, 2003; Kornhauser, 2018; Logan \& Link, 2019), the likelihood that some drug dependent offenders are embellishing, or overstating, their drug dependency has been a long-held suspicion. What this means, therefore, is that the association shown in this study - namely that of self-reported dependency and drug type-may be a consequence of offenders, rightly or wrongly, believing that by self-identifying themselves as 'dependent' they may avoid some of the more serious and potentially negative outcomes of their involvement with drug use and crime. Future research should aim to investigate whether self-identification as dependent is related to increased levels of criminal offending across an individual's criminal trajectory as this would enable practitioners to appropriately respond and intervene among high-rate offenders who use drugs at reasonably high frequencies.

From these results stem a number of policy implications for the criminal justice system more generally. As briefly foreshadowed in the introduction to this paper, programs like drug courts have historically suffered from low treatment retention and success rates, especially among women, younger drug using offenders, and in Australia, Indigenous individuals. These demographic groups have, potentially, been harder to treat due to a lack of understanding regarding how they perceive themselves in relation to their drug using and criminal identities. As such, drug courts, with their focus on rehabilitation and treatment outside of a custodial environment, may benefit from an improved understanding of identity and its influence throughout an individual's life-course. By understanding how an individual drug using offender comes to perceive themselves in terms of their drug dependency, we may be able to further conceptualise, target, and differentially allocate offenders to suitable treatment programs. Furthermore, by recognising that for some individuals, self-identification may occur earlier in their drug using careers, we may be able to intervene, treat, and rehabilitate earlier. For now, this is a proposition that remains to be tested; however, we see this 
as an important area for future research and one which has particular import for both the treatment and drug-crime scholarship, more broadly.

\section{References}

Allen, C., \& Alberici, A.-M. (2018). “Once a Junkie, Always a Junkie”: A Narrative Analysis of Cinematic Representations of the Attribution of Criminality and Deviancy to Heroin Users.

Anglin, M. D., \& Perrochet, B. (1998). Drug use and Crime: A Historical Review of Research Conducted by the UCLA Drug Abuse Research Center. Substance Use \& Misuse, 33(9), 1871-1914. doi: 10.3109/10826089809059325

Anglin, M. D., \& Speckart, G. (1986). Narcotics use, property crime, and dealing: Structural dynamics across the addiction career. [journal article]. Journal of Quantitative Criminology, 2(4), 355-375. doi: 10.1007/bf01064260

Anglin, M. D., \& Speckart, G. (1988). Narcotics and Crime: A Multisample, Multimethod Analysis Criminology, 26(2), 197-233. doi: 10.1111/j.1745-9125.1988.tb00839.x

Asencio, E. K. (2013). Self-Esteem, Reflected Appraisals, and Self-Views:Examining Criminal and Worker Identities. Social Psychology Quarterly, 76(4), 291-313. doi: 10.1177/0190272513504222

Asencio, E. K., \& Burke, P. J. (2011). Does Incarceration Change the Criminal Identity? A Synthesis of Labeling and Identity Theory Perspectives on Identity Change. Sociological Perspectives, 54(2), 163-182. doi: 10.1525/sop.2011.54.2.163

Australian Institute of Health and Welfare. (2011). Substance use among Aboriginal and Torres Strait Islander people. Canberra: AIHW.

Australian Institute of Health and Welfare. (2018). Alcohol, tobacco \& other drugs in Australia.Retrieved from https://www.aihw.gov.au/reports/alcohol/alcohol-tobacco-other-drugs-australia/contents/drug-types/meth/amphetamineand-other-stimulants.

Babor, T. F., McRee, B. G., Kassebaum, P. A., Grimaldi, P. L., Ahmed, K., \& Bray, J. (2007). Screening, Brief Intervention, and Referral to Treatment (SBIRT). Substance Abuse, 28(3), 7-30. doi: 10.1300/J465v28n0303

Bachman, R., Kerrison, E., Paternoster, R., O’Connell, D., \& Smith, L. (2016). Desistance for a Long-Term Drug-Involved Sample of Adult Offenders:The Importance of Identity Transformation. Criminal Justice and Behavior, 43(2), 164-186. doi: $10.1177 / 0093854815604012$

Bamberg, M. (2011). Who am I? Narration and its contribution to self and identity. Theory \& Psychology, 21(1), 3-24. doi: $10.1177 / 0959354309355852$

Baron, S. W. (1999). Street youths and substance use: The role of background, street lifestyle, and economic factors. Youth \& Society, 31(1), 3-26.

Becker, H. (1953). Becoming a Marihuana User. American Journal of Sociology, 59(3), 235-242. doi: 10.1086/221326

Becker, H. S. (1963). Outsiders: Studies in the Sociology of Deviance. Art Worlds (Berkeley).

Bennett, T., \& Holloway, K. (2003). Understanding Drugs, Alcohol and Crime: Understanding Drugs, Alcohol and Crime. Berkshire: McGraw-Hill Education.

Bennett, T., \& Holloway, K. (2005). The association between multiple drug misuse and crime. International Journal of Offender Therapy and Comparative Criminology, 49(1), 63-81.

Bennett, T., \& Holloway, K. (2009). The Causal Connection Between Drug Misuse and Crime. The British Journal of Criminology, 49(4), 513-531. doi: 10.1093/bjc/azp014

Bennett, T., Holloway, K., \& Farrington, D. (2008). The statistical association between drug misuse and crime: A meta-analysis. Aggression and Violent Behavior, 13(2), 107-118. doi: 10.1016/j.avb.2008.02.001

Bergquist, K. L., Fox, H. C., \& Sinha, R. (2010). Self-reports of interoceptive responses during stress and drug cue-related experiences in cocaine- and alcohol-dependent individuals. Experimental and Clinical Psychopharmacology, 18(3), 229-237. doi: $10.1037 / \mathrm{a} 0019451$

Brezina, T., \& Topalli, V. (2012). Criminal Self-Efficacy:Exploring the Correlates and Consequences of a "Successful Criminal" Identity. Criminal Justice and Behavior, 39(8), 1042-1062. doi: 10.1177/0093854812438345

Brochu, S., Brunelle, N., Plourde, C., \& Da Silva, J. (2018). Drugs and crime: a complex relationship (Third, revis and expand ed.). Ottawa, Ontario: University of Ottawa Press. 
Broom, D., \& Stevens, A. (1991). Doubly deviant: Women using alcohol and other drugs. International journal on drug policy, 2(4), 25-27.

Brownfield, D., \& Thompson, K. (2005). Self-Concept and Delinquency: The Effects of Reflected Appraisals by Parent and Peers. Western Criminology Review, 6(1).

Bull, M. (2003). Just treatment: a review of international programs for the diversion of drug related offenders from the criminal justice system: Queensland University of Technology.

Burke, P. J., \& Reitzes, D. C. (1981). The Link Between Identity and Role Performance. Social Psychology Quarterly, 44(2), 83-92. doi: $10.2307 / 3033704$

Burr, A. (1987). Chasing the Dragon: Heroin Misuse, Delinquency and Crime in the Context of South London Culture. The British Journal of Criminology, 27(4), 333-357.

Caulkins, J. P., Disley, E., Tzvetkova, M., Pardal, M., Shah, H., \& Zhang, X. (2016). Modeling the structure and operation of drug supply chains: The case of cocaine and heroin in Italy and Slovenia. International Journal of Drug Policy, 31, 64-73. doi: https://doi.org/10.1016/j.drugpo.2016.02.003

Chaiken, J. M., \& Chaiken, M. R. (1990). Drugs and Predatory Crime. Crime and Justice, 13, 203-239. doi: 10.1086/449176

Chandler, R. K., Fletcher, B. W., \& Volkow, N. D. (2009). Treating drug abuse and addiction in the criminal justice system: improving public health and safety. JAMA, 301(2), 183-190. doi: 10.1001/jama.2008.976

Chen, X., Tyler, K., Whitbeck, L., \& Hoyt, D. (2004). Early Sexual Abuse, Street Adversity, and Drug Use Among Female Homeless and Runaway Adolescents in the Midwest. Journal of drug issues, 34, 1-22. doi: 10.1177/002204260403400101

Cooper, C. S. (2003). Drug Courts: Current Issues and Future Perspectives. Substance Use \& Misuse, 38(11-13), 1671-1711. doi: $10.1081 / \mathrm{JA}-120024237$

Cormier, R. A., Dell, C. A., \& Poole, N. (2004). Women and Substance Abuse Problems. BMC women's health, 4 Suppl 1(Suppl 1), S8-S8. doi: 10.1186/1472-6874-4-S1-S8

Cunneen, C. (2006). Racism, discrimination and the over-representation of Indigenous people in the criminal justice system: Some conceptual and explanatory issues. Current issues in criminal justice, 17(3), 329-346.

Dahl, S. L. (2015). Remaining a user while cutting down: The relationship between cannabis use and identity. Drugs: Education, Prevention and Policy, 22(3), 175-184. doi: 10.3109/09687637.2014.920765

DeLisi, M., Angton, A., Behnken, M. P., \& Kusow, A. M. (2015). Do Adolescent Drug Users Fare the Worst? Onset Type, Juvenile Delinquency, and Criminal Careers. International Journal of Offender Therapy and Comparative Criminology, 59(2), 180-195. doi: 10.1177/0306624X13505426

Dingle, G. A., Cruwys, T., \& Frings, D. (2015). Social Identities as Pathways into and out of Addiction. Frontiers in psychology, 6, 1795-1795. doi: 10.3389/fpsyg.2015.01795

Donath, S. (2003). Women and drugs. In A. Ritter, T. King \& M. A. Hamilton (Eds.), Drug use in Australia: preventing harm: Oxford University Press.

Eddy, N. B., Halbach, H., Isbell, H., \& Seevers, M. H. (1965). Drug dependence: its significance and characteristics. Bulletin of the World Health Organization, 32(5), 721-733.

Erikson, E. H. (1968). Identity: Youth and crisis: WW Norton \& Company.

Everitt, B. J., \& Robbins, T. W. (2016). Drug Addiction: Updating Actions to Habits to Compulsions Ten Years On. Annual Review of Psychology, 67(1), 23-50. doi: 10.1146/annurev-psych-122414-033457 Freeman, K. (2001). New South Wales Drug Court evaluation: health, well-being and participant satisfaction.NSW: NSW Bureau of Crime Statistics and Research.

Freeman, K., \& Fitzgerald, J. (2002). Drug use monitoring of police detainees in New South Wales: The first two years.Sydney: NSW Bureau of Crime Statistics and Research.

Freiberg, A., Payne, J. L., Gelb, K., Morgan, A., \& Makkai, T. (2016). Queensland Drug and Specialist Courts Review: Final Report.Queensland: Queensland Courts Retrieved from https://www.courts.qld.gov.au

French, M. T., \& Zarkin, G. A. (1992). Effects of drug abuse treatment on legal and illegal earnings. Contemporary Policy Issues, 10(2), 98.

Gannoni, A., \& Goldsmid, S. (2017). Readiness to change drug use and help-seeking intentions of police detainees : findings from the DUMA program. Trends and Issues in Crime and Criminal Justice(520), 1-17. 
Gossop, M., Darke, S., Griffiths, P., Hando, J., Powis, B., Hall, W., \& Strang, J. (1995). The Severity of Dependence Scale (SDS): psychometric properties of the SDS in English and Australian samples of heroin, cocaine and amphetamine users. Addiction, 90(5), 607-614. doi: 10.1046/j.1360-0443.1995.9056072.x

Greene, J. M., Ennett, S. T., \& Ringwalt, C. L. (1997). Substance use among runaway and homeless youth in three national samples. American journal of public health, 87(2), 229-235. doi: 10.2105/ajph.87.2.229

Grinman, M., Chiu, S., Redelmeier, D., Levinson, W., Kiss, A., Tolomiczenko, G., . . . Hwang, S. (2010). Drug problems among homeless individuals in Toronto, Canada: Prevalence, drugs of choice, and relation to health status. BMC public health, 10, 94. doi: 10.1186/1471-2458-10-94

Hammersley, R. (2011). Pathways through drugs and crime: Desistance, trauma and resilience. Journal of Criminal Justice, 39(3), 268-272. doi: https://doi.org/10.1016/j.jcrimjus.2011.02.006

Hora, P. F., Schma, W. G., \& Rosenthal, J. T. (1998). Therapeutic jurisprudence and the drug treatment court movement: Revolutionizing the criminal justice system's response to drug abuse and crime in America. Notre Dame L. Rev., $74,439$.

Howard, J. (2000). Social Psychology of Identities. Annual Review of Sociology, 26(1), 367-393. doi: 10.1146/annurev.soc.26.1.367

Hser, Y.-I., Huang, D., Brecht, M.-L., Li, L., \& Evans, E. (2008). Contrasting Trajectories of Heroin, Cocaine, and Methamphetamine Use. Journal of Addictive Diseases, 27(3), 13-21. doi: 10.1080/10550880802122554

Hughes, C. E., Lancaster, K., \& Spicer, B. (2011). How do Australian news media depict illicit drug issues? An analysis of print media reporting across and between illicit drugs, 2003-2008. International Journal of Drug Policy, 22(4), 285-291. doi: https://doi.org/10.1016/j.drugpo.2011.05.008

Johnson, H. (2006). Concurrent Drug and Alcohol Dependency and Mental Health Problems Among Incarcerated Women. Australian \& New Zealand Journal of Criminology, 39(2), 190-217. doi: 10.1375/acri.39.2.190

Kelly, J. F., Bergman, B. G., \& Vilsaint, C. L. (2016). Addiction recovery, mutual-help organizations and social identity Addiction, Behavioral Change and Social Identity (pp. 46-63): Routledge.

Kinner, S. (2006). The post-release experience of prisoners in Queensland: Australian Institute of Criminology Canberra.

Kornhauser, R. (2018). The effectiveness of Australia's drug courts. Australian and New Zealand Journal of Criminology, The, 51(1), 76-98. doi: 10.1177/0004865816673412

Kosten, T. R., Kosten, T. A., McDougle, C. J., Hameedi, F. A., McCance, E. F., Rosen, M. I., . . . Price, L. H. (1996). Gender differences in response to intranasal cocaine administration to humans. Biological Psychiatry, 39(2), 147-148. doi: 10.1016/0006-3223(95)00386-X

Ladwig, G. B., \& Andersen, M. D. (1989). Substance Abuse in Women: Relationship Between Chemical Dependency of Women and Fast Reports of Physical and/or Sexual Abuse. International Journal of the Addictions, 24(8), 739-754. doi: $10.3109 / 10826088909047310$

Leary, M. R., \& Tangney, J. P. (2011). Handbook of self and identity: Guilford Press.

Lemert, E. M. (1951). Social pathology; A systematic approach to the theory of sociopathic behavior.

Little, M. (1990). Young men in prison: The criminal identity explored through the rules of behaviour: Dartmouth Aldershot.

Lloyd, C. (2013). The stigmatization of problem drug users: A narrative literature review. Drugs: Education, Prevention and Policy, 20(2), 85-95. doi: 10.3109/09687637.2012.743506

Logan, M. W., \& Link, N. W. (2019). Taking Stock of Drug Courts: Do They Work? Victims \& Offenders, 14(3), 283-298. doi: 10.1080/15564886.2019.1595249

Mackinem, M. B., \& Higgins, P. (2008). Drug court; constructing the moral identity of drug offenders (Vol. 23). Portland: Ringgold, Inc.

Makkai, T. (1999). Drug use monitoring in Australia (DUMA): a brief description (Vol. no.21.). Canberra: Australian Institute of Criminology.

Makkai, T., \& Payne, J. (2003a). Drugs and Crime: A study of incarcerated male offenders. Canberra: Australian Institute of Criminology.

Makkai, T., \& Payne, J. (2003b). Key Findings from the Drug Use Careers of Offenders (DUCO) Study. Trends \& Issues in Crime \& Criminal Justice. 
Maruna, S., Lebel, T. P., Mitchell, N., \& Naples, M. (2004). Pygmalion in the reintegration process: Desistance from crime through the looking glass. Psychology, Crime \& Law, 10(3), 271-281. doi: 10.1080/10683160410001662762

May, C. (2001). Pathology, identity and the social construction of alcohol dependence. Sociology, 35(2), 385-401.

McIntosh, J., \& McKeganey, N. (2001). Identity and Recovery from Dependent Drug Use: the addict's perspective. Drugs: Education, Prevention and Policy, 8(1), 47-59. doi: 10.1080/09687630124064

McMorris, B. J., Tyler, K. A., Whitbeck, L. B., \& Hoyt, D. R. (2002). Familial and "on-the-street" risk factors associated with alcohol use among homeless and runaway adolescents. Journal of Studies on Alcohol, 63(1), 34-43.

McNemar, Q. (1946). Opinion-attitude methodology. Psychological bulletin, 43(4), 289.

Mead, G. H. (1934). Mind, self and society (Vol. 111): Chicago University of Chicago Press.

Mitchell, O., Wilson, D. B., Eggers, A., \& MacKenzie, D. L. (2012). Assessing the effectiveness of drug courts on recidivism: A meta-analytic review of traditional and non-traditional drug courts. Journal of Criminal Justice, 40(1), 60-71. doi: 10.1016/j.jcrimjus.2011.11.009

Neale, J., Nettleton, S., \& Pickering, L. (2011). Recovery from problem drug use: What can we learn from the sociologist Erving Goffman? Drugs: Education, Prevention and Policy, 18(1), 3-9. doi: 10.3109/09687631003705546

Oyserman, D. (2004). Self-concept and Identity Self and social identity. (pp. 5-24). Malden: Blackwell Publishing.

Oyserman, D., Elmore, K., \& Smith, G. (2012). Self, self-concept, and identity. In M. L. J. Tangney (Ed.), Handbook of Self and Identity. New York: The Guilford Press.

Paternoster, R. (2017). Happenings, Acts, and Actions: Articulating the Meaning and Implications of Human Agency for Criminology. Journal of Developmental and Life-Course Criminology, 3(4), 350-372. doi: 10.1007/s40865-017-0069-2

Paternoster, R., Bachman, R., Bushway, S., Kerrison, E., \& O’Connell, D. (2015). Human Agency and Explanations of Criminal Desistance: Arguments for a Rational Choice Theory. Journal of Developmental and Life-Course Criminology, 1(3), 209-235. doi: 10.1007/s40865-015-0013-2

Paternoster, R., Bachman, R., Kerrison, E., O’connell, D., \& Smith, L. (2016). Desistance from Crime and Identity:An Empirical Test With Survival Time. Criminal Justice and Behavior, 43(9), 1204-1224. doi: 10.1177/0093854816651905

Paternoster, R., \& Bushway, S. (2009). Desistance and the "feared self": toward an identity theory of criminal desistance. The Journal of Criminal Law and Criminology (1973-), 99(4), 1103-1156.

Patterson, E., Sullivan, T., Ticehurst, A., \& Bricknell, S. (2018). Drug use monitoring in Australia: 2015 and 2016 report on drug use among police detainees.Canberra: Australian Institute of Criminology.

Payne, J. L. (2005). Final report on the North Queensland drug court: Australian Institute of Criminology Canberra, Australia. Payne, J. L. (2006). Specialty courts: current issues and future prospects. Canberra, ACT: Australian Institute of Criminology.

Payne, J. L. (2008). The Queensland Drug Court: a recidivism study of the first 100 graduates (Vol. No. 83). Canberra: Australian Institute of Criminology.

Payne, J. L., \& Gaffney, A. (2012). How much crime is drug or alcohol related? Self-reported attributions of police detainees. Trends and Issues in Crime and Criminal Justice [electronic resource](439), 1-6.

Payne, J. L., \& Langfield, C. T. (2020, February 19). When two measures of drug dependency do not accord: prevalence, correlates, and implications for treatment in the criminal justice context. doi: https://doi.org/10.31235/osf.io/tz2ax

Payne, J. L., \& Morgan, A. (2016). Building effective interventions for drug users in the criminal justice system: A review of best practice.Queensland: Queensland Courts.

Pearson, F. S., \& Lipton, D. S. (1999). A meta-analytic review of the effectiveness of corrections-based treatments for drug abuse. The Prison Journal, 79(4), 384-410.

Piazza, N. J., Vrbka, J. L., \& Yeager, R. D. (1989). Telescoping of Alcoholism in Women Alcoholics. International Journal of the Addictions, 24(1), 19-28. doi: 10.3109/10826088909047272

Pollock, J. M. (1999). Criminal women: Anderson Cincinnati, OH.

Poole, N., \& Dell, C. A. (2005). Girls, women and substance use: Canadian Centre on Substance Abuse Ottawa.

Prichard, J., \& Payne, J. L. (2005). Key findings from the Drug Use Careers of Juvenile Offenders study.Canberra: Australian Institute of Criminology. Retrieved from https://aic.gov.au/publications/tandi/tandi304. 
Proctor, S. L., \& Hoffmann, N. G. (2016). The UNCOPE: An effective brief screen for DSM-5 substance use disorders in correctional settings. Psychology of addictive behaviors : journal of the Society of Psychologists in Addictive Behaviors, 30(5), 613-618. doi: 10.1037/adb0000170

Putt, J., Payne, J., \& Milner, L. (2005). Indigenous male offending and substance abuse. Drugs, 1(9), 3.

Rajkumar, A. S., \& French, M. T. (1997). Drug Abuse, Crime Costs, and the Economic Benefits of Treatment. Journal of Quantitative Criminology, 13(3), 291-323. doi: 10.1007/BF02221094

Randall, C. L., Roberts, J. S., Boca, F. K. D., Carroll, K. M., Connors, G. J., \& Mattson, M. E. (1999). Telescoping of landmark events associated with drinking: a gender comparison. Journal of Studies on Alcohol, 60(2), 252-260. doi: 10.15288/jsa.1999.60.252

Reed, B. G. (1985). Drug Misuse and Dependency in Women: The Meaning and Implications of Being Considered a Special Population or Minority Group. International Journal of the Addictions, 20(1), 13-62. doi: 10.3109/10826088509074828

Rocque, M., Posick, C., \& Paternoster, R. (2016). Identities Through Time: An Exploration of Identity Change as a Cause of Desistance. Justice Quarterly, 33(1), 45-72. doi: 10.1080/07418825.2014.894111

Saggers, S., \& Gray, D. (1998). Dealing with alcohol: indigenous usage in Australia, New Zealand and Canada: Cambridge University Press.

Scheibe, L. (2017). Visualising "junkies" and "meth heads" - a visual analysis of the persistent negative reputation of heroin and meth users. Drugs and Alcohol Today, 17(1), 40-49. doi: 10.1108/DAT-11-2016-0027

Shaffer, D. K. (2011). Looking Inside the Black Box of Drug Courts: A Meta-Analytic Review. Justice Quarterly, 28(3), 493-521. doi: 10.1080/07418825.2010.525222

Shand, F. L., Degenhardt, L., Slade, T., \& Nelson, E. C. (2010). Sex differences amongst dependent heroin users: Histories, clinical characteristics and predictors of other substance dependence. Addictive Behaviors, 36(1), 27-36. doi: 10.1016/j.addbeh.2010.08.008

Shannon, L. M., Jones, A. J., Newell, J., \& Payne, C. (2018). Examining Individual Characteristics and Program Performance to Understand Two-Year Recidivism Rates Among Drug Court Participants: Comparing Graduates and Terminators. International Journal of Offender Therapy and Comparative Criminology, 62(13), 4196-4220. doi: 10.1177/0306624x18769602

Shapiro, H. (2002). From Chaplin to Charlie-cocaine, Hollywood and the movies. Drugs: Education, Prevention and Policy, 9(2), 133-141.

Shinebourne, P., \& Smith, J. A. (2009). Alcohol and the self: An interpretative phenomenological analysis of the experience of addiction and its impact on the sense of self and identity. Addiction Research \& Theory, 17(2), 152-167.

Shover, N. (1996). Great Pretenders: Pursuits and Careers of Persistant Thieves: Boul der, CO: Westview.

Snowball, L., \& Weatherburn, D. (2006). Indigenous over-representation in prison: The role of offender characteristics. BOCSAR NSW Crime and Justice Bulletins, 20.

Spencer, P. (2012). To dream the impossible dream? Therapeutic jurisprudence in mainstream courts. Paper presented at the International Conference on Law and Society.

Spooner, C., \& Hetherington, K. (2005). Social determinants of drug use: National Drug and Alcohol Research Centre, University of New South Wales

Sproule, B. A., Busto, U. E., Somer, G., Romach, M. K., \& Sellers, E. M. (1999). Characteristics of Dependent and Nondependent Regular Users of Codeine. Journal of Clinical Psychopharmacology, 19(4), 367-372.

Stafford, J., \& Bums, L. (2013). Australian Trends in Ecstasy and Related Drug Markets 2012: Findings from the Ecstasy and Related Drugs Reporting System (EDRS) Sydney: National Drug and Alcohol Research Centre, University of New South Wales Retrieved from https://ndarc.med.unsw.edu.au/sites/default/files/ndarc/resources/EDRSStevens, A., Berto, D., Frick, U., Kerschl, V., McSweeney, T., Schaaf, S., . . Werdenich, W. (2007). The Victimization of Dependent Drug Users:Findings from a European Study, UK. European Journal of Criminology, 4(4), 385-408. doi: 10.1177/1477370807080719

Taylor, S. (2008). Outside the outsiders: Media representations of drug use. Probation Journal, 55(4), 369-387. doi: $10.1177 / 0264550508096493$

Teesson, M., Marel, C., Darke, S., Ross, J., Slade, T., Burns, L., . . . Mills, K. L. (2017). Trajectories of heroin use: 10-11-year findings from the Australian Treatment Outcome Study. Addiction, 112(6), 1056-1068. doi: 10.1111/add.13747 
Thompson, S. J., Rew, L., Barczyk, A., McCoy, P., \& Mi-Sedhi, A. (2009). Social Estrangement: Factors Associated with Alcohol or Drug Dependency among Homeless, Street-Involved Young Adults. Journal of Drug Issues, 39(4), 905-929. doi: $10.1177 / 002204260903900407$

Tiger, R. (2013). Judging addicts: Drug courts and coercion in the justice system (Vol. 6): NYU Press.

Tuchman, E. (2010). Women and Addiction: The Importance of Gender Issues in Substance Abuse Research. Journal of Addictive Diseases, 29(2), 127-138. doi: 10.1080/10550881003684582

U.S. Department of Justice. (2002). I-ADAM in Eight Countries: Approaches and Challenges.Washington, D.C.: U.S. Department of Justice Retrieved from https://www.ncjrs.gov/pdffiles1/nij/189768.pdf.

Veysey, B., \& Rivera, L. (2017). Implicit Criminal Identity and Age: Implications for Criminal Persistence and Desistance. Criminal Justice and Behavior, 44(10), 1249-1261. doi: 10.1177/0093854817722173

Voce, A., \& Sullivan, T. (2019). Drug use monitoring in Australia: Drug use among police detainees, 2018.Canberra: Australian Institute of Criminology Retrieved from https://aic.gov.au/publications/sr/sr18.

Volkow, N., \& Li, T.-K. (2004). Drug addiction: the neurobiology of behaviour gone awry. Nature Reviews Neuroscience, 5(12), 963-970. doi: 10.1038/nrn1539

Volkow, N., Wang, G.-J., Fowler, J. S., Tomasi, D., Telang, F., \& Brookhaven National, L. (2011). Addiction: Beyond dopamine reward circuitry. Proceedings of the National Academy of Sciences of the United States of America, 108(37), 15037-15042. doi: 10.1073/pnas.1010654108

Volkow, N., Wang, G. J., Fowler, J. S., Logan, J., Gatley, S. J., Wong, C., . . . Pappas, N. R. (1999). Reinforcing effects of psychostimulants in humans are associated with increases in brain dopamine and occupancy of $\mathrm{D}(2)$ receptors. The Journal of pharmacology and experimental therapeutics, 291(1), 409-415.

Vryan, K., Adler, P. A., \& Adler, P. (2003). Identity. In L. R. N. Herman-Kinney (Ed.), Handbook of symbolic interactionism (pp. 367-390). Lanham, MD: AltaMira Press.

Wagner, F. A., \& Anthony, J. C. (2002). From first drug use to drug dependence; developmental periods of risk for dependence upon marijuana, cocaine, and alcohol. Neuropsychopharmacology: official publication of the American College of Neuropsychopharmacology, 26(4), 479. doi: 10.1016/S0893-133X(01)00367-0

Waldorf, D., \& Biernacki, P. (1981). The Natural Recovery from Opiate Addiction: Some Preliminary Findings. Journal of Drug Issues, 11(1), 61-74. doi: 10.1177/002204268101100104

Wasilow-Mueller, S., \& Erickson, C. K. (2001). Reviews: Drug Abuse and Dependency: Understanding Gender Differences in Etiology and Management. Journal of the American Pharmacists Association, 41(1), 78-90. doi: 10.1016/S00030465(15)32996-7

Weatherburn, D. (2014). Arresting incarceration: Pathways out of Indigenous imprisonment: Aboriginal Studies Press.

Weatherburn, D., \& Holmes, J. (2010). Re-thinking indigenous over-representation in prison. Australian Journal of Social Issues, 45(4), 559-576.

Weatherburn, D., Topp, L., Midford, R., \& Allsopp, S. (2000). Drug crime prevention and mitigation: A literature review and research agenda: Government Press.

Westermeyer, J., \& Boedicker, A. E. (2000). Course, Severity, and Treatment of Substance Abuse Among Women Versus Men. The American Journal of Drug and Alcohol Abuse, 26(4), 523-535. doi: 10.1081/ADA-100101893

Wundersitz, J. (2007). Criminal justice responses to drug and drug-related offending: are they working? : Australian Institute of Criminology Canberra. 